\title{
An Evaluation of Discover MyPlate: An Inquiry- Based Nutrition Education Curriculum for Kindergarten Students
}

\author{
Beth L Metzler', Alan C Yen², Amber R Haroldson², Carol A Friesen ${ }^{3 *}$ \\ ${ }^{1}$ Master of Science, College of Applied Sciences and Technology. \\ ${ }^{2}$ Assistant Professor, Department of Family and Consumer Science, Ball State University, Muncie, IN, United States \\ ${ }^{3}$ Professor of Nutrition and Dietetics, Department of Nutrition and Health Science, Ball State University, Muncie, IN, United State
}

Received: January 02, 2017; Accepted: February 03,2017; Published: February 20, 2017

*Corresponding author: Carol A Friesen, Professor of Nutrition and Dietetics, Department of Nutrition and Health Science, Ball State University, 2000 W. University Ave., Muncie, IN 47306, Phone: 1-765-285-5925; Fax: 1-765-285-3210; E-mail: cfriesen@bsu.edu

\begin{abstract}
The prevalence of childhood obesity has tripled in the past 30 years. Establishing healthy eating and physical activity patterns at an early age lowers the risk of obesity, making schools an important partner in establishing healthy lifestyle in children. Using an experimental design, this study was conducted in a rural Midwestern school district to examine the impact of five 30-minute nutrition education lessons from Discover MyPlate with a focus on the nutrition knowledge, attitudes, and healthy eating behaviors of kindergarten students. The results suggest that Discover MyPlate was effective for teaching children about healthy eating. However, no evidence was obtained to indicate eating behaviors were immediately affected.
\end{abstract}

Keywords: Discover Myplate; Nutrition Education; Team Nutrition; Childhood Obesity; Nutrition Curriculum; Myplate; Healthy Eating; Kindergarten; Students

\section{Introduction}

According to the United States Department of Agriculture, United States Department of Health and Human Services (2010), the average child 4 to 8 years old needs an estimated 1,200-1,400 calories per day, with a recommended daily intake of 5 ounces grain, $1 \frac{1}{2}$ cups vegetables, $1 \frac{1}{2}$ cups fruit, $2 \frac{1}{2}$ cups dairy, and 4 ounces protein. MyPlate, a depiction of how to build a healthy meal, serves to remind people to eat from all five food groups and urges individuals to make half of their plate fruits and vegetables [17].

National Health and Nutrition Examination Survey data indicate current consumption patterns for fruit among children 4 years of age and older, and vegetables for children 2 years of age and older, are below recommended levels $[10,12]$ noted a downward trend in fruit consumption as children get older and a deficit in dark green vegetable consumption altogether.

Analysis of food consumption data from 1989 through 2008 indicates a significant increase in savory and sweet snacks in the diets of children aged 2 to 6 year [4]. The consumption of high-fat processed foods and sugar-sweetened beverages that contribute excess calories to children's diets, along with the increased use of technology and decrease in physical activity, have significantly impacted children's health [9].

Concordantly, the prevalence of obesity for children aged 2 to 19 has tripled in the past 30 years from 5.5 percent in 1980 to 16.9 percent in 2012 [6]. As seen in a cohort study of 9,000 students, the prevalence of obesity increased from 12.4 percent overweight or obese in kindergarten to 20.8 of the same students by eighth grade [3].

With the current diets of children and the increased rates of overweight and obesity, the Academy of Nutrition and Dietetics recognizes the need for nutrition education programs to influence children's dietary intake [14]. While parents and early feeding practices greatly affect a child's eating behavior, formal education in the schools and community programs can play a significant role in establishing these behaviors [16]. Especially if the child lacks an avenue for learning about nutrition in the family or home, nutrition education may have to rely on sources outside the home [10].

The United States Department of Agriculture's Team Nutrition released the Discover MyPlate nutrition education curriculum for kindergarten students in June 2014 (White et al. 2014). Although formative research was completed in developing the curriculum, no published evaluation of the curriculum has been identified. The purpose of this study was to measure the impact of five 30-minute nutrition education lessons from the Discover MyPlate curriculum on the nutrition knowledge, attitudes, and healthy eating behaviors of kindergarten students in a rural, Midwestern school district. 


\section{Methods}

This program evaluation was deemed "non-human subject research" by the University's Institutional Review Board. The intervention school submitted a letter requesting that this nutrition education curriculum be implemented. Previous data from the intervention school corporation revealed 46 percent overweight and obesity rate among students, with only 18 percent eating 2 fruits and 3 vegetables daily, [1]. Additionally, 54.1 percent of the students in the target elementary school received a free or reduced priced lunch [8].

In collaboration with each kindergarten teacher, a letter of information was sent home with each student outlining the upcoming Discover MyPlate program evaluation. Two surveys, student and parent, were created based on the Discover MyPlate objectives, as well as methodology and instruments from similar program evaluations $[2,5]$. The student survey was piloted on six kindergarten students from outside the intervention school Three experts in the field tested the student and parent surveys for content and construct validity. Improvements to wording pictures, answer choices, and logistics were made prior to giving the assessments (Figures $1 \& 2$ )

The validated and piloted student pre-assessment was given to all full-day kindergarten students in four classrooms from the intervention school. Students were called into the hallway to complete the assessment one on one with either the primary researcher or one of the four trained research assistants. Absent students were noted and given the assessment within a few days.

Using a quasi-experimental, convenience sample design, two classrooms were randomly selected to receive the five lessons from Discover MyPlate while the remaining two classrooms served as controls.

The Discover MyPlate curriculum was condensed into five 30-minute lessons to cover key objectives within the stated time agreement with the intervention school. The five lessons covered the following topics:

- The five food groups
Student Survey Questions (Qualtrics)

1. Student's gender

Student's teacher

3. Student's name

4. Do you know what a food group is?

5. How many food groups do you think there are?

6. Can you tell me the names of the food groups? (Click the box next to each group he/she can name.)

- Fruits

- Vegetables

- Protein/ Meat

- Dairy/ Milk

- Grains/ Breads

7. MyPlate is a picture that reminds people what to eat every day to be healthy. Can you point to the MyPlate picture? (student will choose from three pictures)

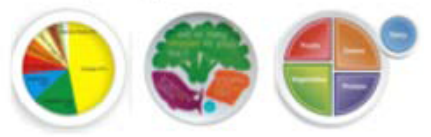

8. What food group do these foods belong in? (a picture of various grains).

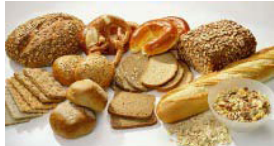

9. Have you eaten any fruit today? (Assessments done in afternoon.)

10. Have you eaten any vegetables today?

11. What is your favorite colorful fruit?

12. What is your favorite colorful vegetable
13. Have you eaten a kiwi before?

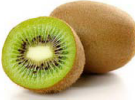

14. How does eating this fruit make you feel?
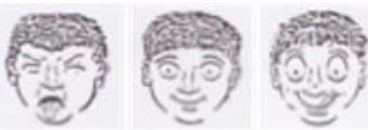

15. How does eating this vegetable make you feel?

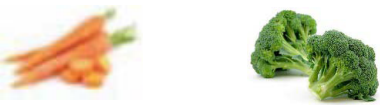

16. How about this vegetable? (broccoli)

17. Is this a healthy choice to fuel your body so you can play?
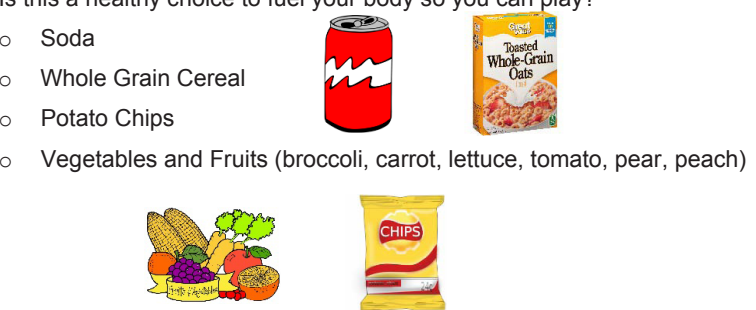

Figure 1: Child Assessment 


\section{Discover MyPlate}

\section{PARENT/GUARDIAN SURVEY}

Child's Name:

Teacher

1. In the past month, have you noticed any changes in your child's eating behaviors?

$\square$ No, no change

Yes, a positive change (e.g., they are eating and asking for healthier foods!)

If yes, what changes have you seen?

2. In general, does your child usually like eating fruits?
$\square$ No
$\square$ Yes

3. In general, does your child usually like eating vegetables?

$\square$ No

$\square$ Yes

4. In the past month, have you noticed a change in your child's attitude toward eating fruits?

$\square$ No, no change

$\square$ Yes, a positive change (e.g., eating more fruit/asking for fruit)

$\square$ Yes, a negative change (e.g., not willing to eat fruit/never asking for fruit)

5. In the past month, have you noticed a change in your child's attitude toward eating vegetables?

$\square$ No, no change

$\square$ Yes, a positive change (e.g., eating more veggies/asking for veggies or a salad)

$\square$ Yes, a negative change (e.g., not willing to eat veggies/never asking for veggies)

6. Has your child tried eating a NEW fruit recently?

$\square$ No

$\square$ Yes. If yes, what fruit/fruits?

7. Has your child tried eating a NEW vegetable recently?

$\square$ No

$\square$ Yes. If yes, what vegetable(s)?

Please return to your child's kindergarten teacher by Friday x/x/2015

Figure 2: Parent Assessment

- Healthy meals with MyPlate

- $\quad$ Eating the rainbow with fruits and vegetables

- The importance of breakfast
- Physical activity and foods that fuel your body for play

Students in the treatment group learned the five food groups through a variety of activities, including interactive teachings, games, food cards, taste testing, food group characters, a song, a 
snack, worksheets, "Emergent Reader" booklets, and take-home activities. Additional activities included in the curriculum that were not used in this study due to time constraints included story time, dramatic play, and a gardening demonstration.

After the intervention, all kindergarten students were given the post assessment in the same manner as the pre-assessment. The parent/guardian surveys, attached to a second letter of information, were sent home with all students. The letter asked parents to participate in a short survey about any changes they may have noticed in their child over the past month.

Data was coded for classroom and treatment or control group. All missing fields within the data were re-coded as "I don't know," since research assistants were advised to leave the question blank if the child could not give an answer. Data was analyzed using cross-tabulation, paired t-test, one way analysis of variance, and Pearson's Chi Square from the SPSS version 22 statistical analysis software (IBM Corporation). Significance was set at an alpha level of $\mathrm{p}=0.05$.

\section{Results}

A total of 95 students were included in this program evaluation (48 treatment group; 47 control group). Overall, 49.5\% ( $n=47)$ of the students were male and $50.5 \%(n=48)$ were female. No significant differences were detected for the pre-assessment between the control and treatment groups on any variables.

Data from the post-assessment indicated students in the treatment group were significantly more likely than the control group to: acknowledge what is a food group, state the correct number of food groups, give the names of each food group, identify the MyPlate logo, and assign foods to their corresponding food group.

When asked, "Do you know what a food group is?" the treatment group increased from 6.5 percent at pre-assessment to 79.2 percent at post-assessment who responded "yes". When compared to the control group, who increased from zero at pre-assessment to $37.8 \%$ at post assessment, this finding was significant $(\mathrm{p}<0.05)$. For the ability to state there are five food groups, the percentage of students from the pre- to postassessment increased from 22.5 percent to 95.8 percent, while the control group decreased from 10.5 percent to 2.5 percent, causing a significant difference between groups $(\mathrm{p}<0.05)$

In the treatment group, the greatest increase in knowledge for the ability to name each food group from pre- to post-assessment was for "dairy" (72.9 percent) followed by "vegetables" (68.6 percent), "fruit" (56.3 percent), "protein" (48.5 percent), and "grains" (45.8 percent). All food groups had significant differences between groups (0.05). The percentage of students from pre- to post-assessment who were able to identify the MyPlate logo increased from 30 to 92 percent in the treatment group, while the control group decreased from 34 to 17 percent, causing a significant difference between groups $(p<0.05)$. Also, students were shown a picture of foods in the grains group and vegetable group. For both pictures, there was a difference in the number of students who could say "grains" or "vegetables", with the treatment group increasing significantly $(\mathrm{p}<0.05)$. The results of treatment versus control groups for MyPlate food group knowledge are summarized in Table 1.

Although colorful fruits and vegetables were a focus of one lesson, there was no difference between treatment and control group in students' ability to name a colorful fruit $(\mathrm{p}=0.124)$ and vegetable ( $p=0.902)$. Fruit and vegetable consumption, as well as attitude toward three healthy foods (two of which were tasted by the treatment group), had no significant difference between treatment and control groups ( $p>0.05)$. Lastly, there was no difference between groups at post-assessment for ability to select healthy foods ( $\mathrm{p}>0.05)$, as the majority of students were already able to identify healthy versus non-healthy choices during the pre-assessment.

Fifty (52.6\% response rate) parents/guardians responded to the survey sent home with all students after intervention. No differences were detected between groups in the parents' perception of their child's eating behaviors, attitudes toward fruits and vegetables, or willingness to trying a new fruit/ vegetable.

\section{Discussion}

Although students receiving the Discover MyPlate lessons showed significant improvement in nutrition knowledge over their non-intervention peers, no significant nutrition behavior or attitude changes were detected. Other nutrition programs, however, have been successful in these areas [7] focused their education and assessments on several health behavior changes, some showing significant improvement and others not. Discover MyPlate promoted a broader understanding of nutrition and MyPlate, but perhaps focusing on multiple behaviors and specific

Table 1: Treatment vs. Control: MyPlate Food Group Knowledge (n=95)

\begin{tabular}{|c|c|c|c|c|}
\hline Question & Category & Timing & $\mathbf{X}^{2}$ & $\mathbf{P}$ \\
\hline $\begin{array}{l}\text { Do You Know what a } \\
\text { food group is? }\end{array}$ & & $\begin{array}{l}\text { Per } \\
\text { Post }\end{array}$ & $\begin{array}{c}3.1 \\
16.5\end{array}$ & $\begin{array}{c}0.078 \\
<0.001\end{array}$ \\
\hline $\begin{array}{l}\text { How many food groups } \\
\text { do you think there are? }\end{array}$ & & $\begin{array}{l}\text { Per } \\
\text { Post }\end{array}$ & $\begin{array}{l}17.3 \\
81.4\end{array}$ & $\begin{array}{c}0.506 \\
<0.001\end{array}$ \\
\hline \multirow{5}{*}{$\begin{array}{l}\text { Can you tell me the } \\
\text { names of the food } \\
\text { groups? }\end{array}$} & Fruit & $\begin{array}{l}\text { Per } \\
\text { Post }\end{array}$ & $\begin{array}{c}0.1 \\
13.0\end{array}$ & $\begin{array}{c}0.701 \\
<0.001\end{array}$ \\
\hline & Vegetables & $\begin{array}{l}\text { Per } \\
\text { Post }\end{array}$ & $\begin{array}{c}0.9 \\
25.3\end{array}$ & $\begin{array}{c}0.349 \\
<0.001\end{array}$ \\
\hline & Protein & $\begin{array}{l}\text { Per } \\
\text { Post }\end{array}$ & $\begin{array}{c}* \\
28.0\end{array}$ & $\begin{array}{c}* \\
<0.001 \\
\end{array}$ \\
\hline & Dairy & $\begin{array}{l}\text { Per } \\
\text { Post }\end{array}$ & $\begin{array}{c}* \\
24.3 \\
\end{array}$ & $\begin{array}{c}* \\
<0.001\end{array}$ \\
\hline & Grains & $\begin{array}{l}\text { Per } \\
\text { Post }\end{array}$ & $\begin{array}{c}1.0 \\
29.7\end{array}$ & $\begin{array}{c}0.302 \\
<0.001\end{array}$ \\
\hline $\begin{array}{c}\text { Can you point to the My } \\
\text { Plate picture? }\end{array}$ & & $\begin{array}{l}\text { Per } \\
\text { Post }\end{array}$ & $\begin{array}{c}1.3 \\
53.5\end{array}$ & $\begin{array}{c}0.863 \\
<0.001\end{array}$ \\
\hline \multirow{2}{*}{$\begin{array}{l}\text { In what food group do } \\
\text { you think these foods } \\
\text { belong }\end{array}$} & $\begin{array}{l}\text { Picture of } \\
\text { grains }\end{array}$ & $\begin{array}{l}\text { Per } \\
\text { Post }\end{array}$ & $\begin{array}{c}1.0 \\
30.5\end{array}$ & $\begin{array}{c}0.320 \\
<0.001\end{array}$ \\
\hline & $\begin{array}{c}\text { Picture of } \\
\text { vegetables }\end{array}$ & $\begin{array}{l}\text { Per } \\
\text { Post }\end{array}$ & $\begin{array}{c}1.4 \\
21.2\end{array}$ & $\begin{array}{c}0.486 \\
<0.001\end{array}$ \\
\hline
\end{tabular}

*No student provided a correct answer . 
improvements would have resulted in significant behavior changes [11] served bi-weekly healthy snacks over a fourweek intervention period that resulted in improved snacking behaviors. Due to limited resources and time, students in this program evaluation had only two opportunities for healthful snacks. The more exposure a child has, the more likely they will prefer healthful foods, impacting dietary intake of children [11]. Research also indicates it can take up to 10 to 15 new food exposures for a person to show a shift in taste preferences and attitude toward certain foods [13].

Though measures from the parent survey were not significant when compared to the control group, nearly one third of responding parents from the treatment group reported a positive change in their child's eating behaviors. Parents were able to comment on any changes noticed in their child's behaviors/ attitudes. Six comments from the treatment group, as opposed to 1 from the control group, indicated their child was asking for more fruits and/or vegetables.

Other comments relayed by parents of the treatment group were related directly to the Discover MyPlate lessons. For example, "She talks about what food groups her foods belong to," and "more aware of what is on his plate." On the contrary, comments from the control group may have been related to the student assessment questions but were not tied to the Discover MyPlate lessons. For example, "she tells us sugar and junk food is bad for us," and "asks for healthier drinks."

Limitations are seen in the design and methods of this study. First, condensing the curriculum may have lost some of the effects of the all-inclusive program. Second, the data was not filtered for students present at less than majority of the lessons. Third, other community efforts to promote health and wellness may have skewed the data, causing some measures to not be statistically significant. Fourth, students may have been distracted during the assessments as the location of the assessment was confined to the hallway outside of the kindergarten classrooms, where distractions may have been present.

Some strengths in this program evaluation exist. First, the intervention school requested this nutrition education resulting in enthusiastic collaboration with kindergarten teachers and complete participation from all possible subjects. Second, the presence of a control group allowed for a more accurate evaluation of changes caused from the intervention alone. Third, the child survey instrument was piloted and validated, with changes made to the survey prior to starting data collection. Fourth, all lessons were taught by the primary researcher to provide uniformity between the two treatment classrooms.

\section{Curriculum}

Discover MyPlate was an excellent and comprehensive curriculum. It is user friendly, suitable for elementary teachers and extension educators alike. Discover MyPlate has suggestions to guide the user based on allotted time frame to teach the curriculum; there are enough activities and event suggestions to spread this curriculum throughout the entire school year.
Strengths of Discover MyPlate include its highly current standards, newly innovative education tactics, engaging supply of education materials, and narrowed focus on a target age group (kindergarten). This curriculum, however, could be modified to reach other levels of elementary students or even preschoolers.

Discover MyPlate is a curriculum that promotes healthy eating practices for children and enhances children's nutrition knowledge. As it was reported through the parent survey, a parent of a child that completed this program noted this positive change: "Through Discover MyPlate, my child seems to better understand why he has always been given healthy foods at home." As knowledge about nutrition increases, interest in health flourishes, and healthful behavior changes are more likely to occur.

\section{Conclusion}

Based on assessment measures and parent comments about change perceived in their student, it can be stated that the Discover MyPlate nutrition education curriculum for kindergarten students is effective for teaching children about healthy eating. This curriculum appeared to have successfully provided kindergarten students a foundation of nutrition standards and guidelines from MyPlate. Despite no significant behavioral or attitude changes assessed from this program, the full impact of Discover MyPlate on the future of these students is unknown.

\section{References}

1. Brant T. Selma Moves to Improve: Year two annual report to LPSC constituents PEP Grant. 2014.

2. Calfas KJ, Sallis JF and Nader PR. The development of scales to measure knowledge and preference for diet and physical activity behavior in 4- to 8-year-old children. Journal of Developmental And Behavioral Pediatrics. 1991;12(3):185-190.

3. Cunningham SAP, Kramer MRP and Narayan KMV. Incidence of childhood obesity in the united states. The New England Journal of Medicine. 2014;370(5):403-411.

4. Ford CN, Slining MM and Popkin BM. Trends in dietary intake among US 2- to 6-year-old children, 1989-2008. Journal of the Academy of Nutrition \& Dietetics. 2013;113(1):35-42. doi: 10.1016/j. jand.2012.08.022.

5. Friesen-Schroeder CA, Ferguson DE and Wray PS. 5 A Day-for Better Health!: 3rd-4th Grade Curriculum. Indianapolis, IN: Marion County Health Department Bureau of Community Health Services. 1994

6. Fryar CD, Carroll MD and Ogden CL. Prevalence of obesity among children and adolescents: United States, trends 1963-1965 through 2009-2010. Division of Health and Nutrition Examination Surveys. 2012.

7. Hu C, Ye D, Li Y, Huang Y, Li L, Gao Y, et al. Evaluation of a kindergartenbased nutrition education intervention for pre-school children in China. Public Health Nutrition. 2010;13(2):253-260. doi: 10.1017/ S1368980009990814.

8. Indiana Department of Education. School enrollment by ethnicity and free/reduced price meal status. 2015. Available from: http://www. doe.in.gov/accountability/find-school-and-corporation-data-reports

9. Katz DL. Unfattening our children: Forks over feet. International Journal of Obesity. 2011;35(1):33-37. doi: 10.1038/ijo.2010.218. 
10. Lueke L. Devouring childhood obesity by helping children help themselves. Journal of Legal Medicine. 2011;32(2):205-220.

11. Matvienko O. Impact of a nutrition education curriculum on snack choices of children ages six and seven years. Journal of Nutrition Education \& Behavior. 2007;39(5):281-285.

12. Nielsen SJ, Rossen LM, Harris DM and Ogden CL. Fruit and vegetable consumption of U.S. youth, 2009-2010. NCHS Data Brief. 2014;(156):18.

13. No Kid Hungry Center for Best Practices. What makes nutrition education programs effective? 2015.

14. Ogata BN and Hayes D. Position of the Academy of Nutrition and Dietetics: Nutrition guidance for healthy children ages 2 to 11 years. Journal of the Academy of Nutrition \& Dietetics. 2015;114(8):12571276. doi: 10.1016/j.jand.2014.06.001.

15. Prelip M, Kinsler J, Chan Le, T Erausquin, JT, Slusser W. Evaluation of a school-based multicomponent nutrition education program to improve young children's fruit and vegetable consumption. Journal of Nutrition Education \& Behavior. 2012;44(4):310-318. doi: 10.1016/j. jneb.2011.10.005

16. Turner L, Chaloupka, FJ. Slow progress in changing the school food environment: Nationally representative results from public and private elementary schools. Journal of the Academy of Nutrition \& Dietetics. 2012;112(9):1380-1389. doi: 10.1016/j.jand.2012.04.017

17. United States Department of Agriculture. About us: My Plate. 2015. Available from: https://www.choosemyplate.gov/MyPlate

18. US Department of Agriculture, US Department of Health and Human Services. Dietary Guidelines for Americans, 2010. US Government Printing Office, $7^{\text {th }}$ ed. Washington DC. 2010. Retrieved from http://www.health.gov/dietaryguidelines/dga2010/DietaryGuidelines2010.pdf 